\title{
PERAMALAN NILAI EKSPOR PRODUK INDUSTRI ALAS KAKI MENGGUNAKAN MODEL ARIMAX DENGAN EFEK VARIASI KALENDER
}

\author{
Alma Kurnia Riska ${ }^{1, \text { a) }}$, Ibnu Hadi ${ }^{1, b)}$ \\ ${ }^{1}$ Program Studi Matematika, Fakultas Matematika dan Ilmu Pengetahuan Alam, Universitas Negeri Jakarta \\ Email: a)alma.kurnia@gmail.com, ${ }^{\text {b) }}$ ibnu_hadi@unj.ac.id
}

\begin{abstract}
ARIMAX model is an ARIMA model with additional variables. Additional variables used for time series data with calendar variations in the form of dummy variables. In this paper, we will calculate the forecast of exports value of footwear industry products from July 2019 to June 2020 using the ARIMAX model with calendar variation effects. The effect of calendar variations found on the export value data of footwear industry products is the Eid Al-Fitr holiday. The data used in this paper are data on the export value of footwear industry products from January 2010 to June 2019. ARIMAX modeling is done by combining dummy regression models from actual data and ARIMA models from residual data.
\end{abstract}

Keywords: Forecasting, Export Value, Calendar Variation, Dummy Variables, ARIMAX

\begin{abstract}
Abstrak
Model ARIMAX adalah model ARIMA dengan peubah tambahan. Peubah tambahan yang digunakan untuk data deret waktu dengan variasi kalender berupa variabel dummy. Pada penelitian ini, akan dilakukan penghitungan peramalan nilai ekspor produk industri alas kaki bulan Juli 2019 sampai dengan Juli 2020 dengan menggunakan model ARIMAX dengan efek variasi kalender. Efek variasi kalender yang ditemukan pada data nilai ekspor produk industri alas kaki adalah libur hari raya Idul Fitri. Data yang digunakan pada makalah ini yaitu data nilai ekspor produk industri alas kaki mulai dari bulan Januari tahun 2010 sampai dengan bulan Juni tahun 2019. Pemodelan ARIMAX dilakukan dengan menggabungkan model regresi dummy dari data aktual dan model ARIMA dari data residual.
\end{abstract}

Kata-kata kunci: Peramalan, Nilai Ekspor, Variasi Kalender, Variabel Dummy, ARIMAX

\section{PENDAHULUAN}

Tingkat perekonomian di suatu negara menjadi salah satu tolok ukur dalam menentukan kualitas suatu negara. Dalam perkembangannya, salah satu faktor yang mempengaruhi tingkat perekonomian suatu negara adalah pendapatan suatu negara yang biasa disebut devisa negara. Devisa Negara Indonesia berasal dari berbagai sumber, salah satunya adalah kegiatan ekspor-impor. Kegiatan ekspor merupakan kegiatan jual beli yang dilakukan antar negara. Kegiatan tersebut dilakukan hampir oleh seluruh negara yang ada di dunia, salah satunya Indonesia. Suatu nilai ekspor yang dinyatakan dalam 
US Dollar merupakan salah satu data deret waktu atau time series yang disajikan dalam kurun waktu bulanan.

Salah satu sektor yang nilai perdagangannya terus meningkat adalah sektor industri alas kaki, karenanya industri alas kaki adalah salah satu industri yang menjanjikan dimasa yang akan datang bagi pertumbuhan perekonomian Indonesia. Agar nilai ekspor industri alas kaki terus meningkat maka harus dikendalikan dengan menyusun strategi yang tepat. Strategi tersebut dapat terwujud apabila mengetahui kondisi yang akan datang, untuk itu diperlukan adanya suatu kegiatan peramalan mengenai kondisi nilai ekspor di masa yang akan datang. Data ekspor produk industri alas kaki merupakan data ekspor bulanan sehingga memungkinkan adanya pola musiman. Pola musiman yang ditemukan pada data ekspor industri alas kaki adalah libur hari raya Idul Fitri yang periode musimannya tidak tetap. Oleh karena itu, peramalan akan dilakukan menggunakan model ARIMAX yang merupakan model ARIMA dengan peubah tambahan (Cryer dan Chan, 2008). Peubah tambahan yang digunakan pada data dengan variasi kalender adalah variabel dummy.

Peramalan menggunakan model ARIMAX dengan peubah tambahan berupa variabel dummy telah banyak dilakukan diantaranya Peramalan Volume Penjualan Tiket Mobil dengan Model Variasi Kalender (Studi Kasus: Penjualan Tiket Ferry Khusus Mobil di Pelabuhan Penyebrangan Kariangau Balikpapapn) (Apriyadi dkk, 2015) dan Peramalan Jumlah Penumpang Kereta Api Fajar Utama Yogyakarta - Pasar Senen Menggunakan Variasi Kalender ARIMAX (Noer dkk, 2016). Penelitian ini bertujuan untuk mengetahui model ARIMAX dalam meramalkan nilai ekspor produk industri alas kaki dan hasil peramalan nilai ekspor produk industri alas kaki pada bulan Juli 2019 sampai dengan bulan Juni 2020.

\section{METODE}

\section{Model Regresi dengan Efek Variasi Kalender}

Regresi dalam konteks time series memiliki bentuk yang sama dengan regresi linier umum. Dengan mengasumsikan output atau bentuk respon $y_{t}$ yang dipengaruhi oleh kemungkinan data input atau predictor, dimana inputnya merupakan fix dan diketahui, hubungan ini dapat ditunjukkan dengan model regresi linier (Shumway dan Stoffer, 2006). Model regresi linier untuk data yang memiliki variasi kalender adalah,

$$
y_{t}=\beta_{0}+\beta_{1} D_{1, t}+\beta_{2} D_{2, t}+\ldots+\beta_{n} D_{n, t}
$$

Keterangan:

$D_{n, t}=$ variabel dummy untuk efek variasi kalender ke-n

$t \quad=$ banyaknya bulan dalam 1 tahun

Metode pendugaan parameter model regresi dummy menggunakan metode Ordinary Least Square (OLS). Prinsip dari OLS adalah menentukan nilai parameter-parameter yang tidak diketahui sehingga menghasilkan jumlah kuadrat sisaan yang bernilai seminimal mungkin (Gujarati, 2004).

\section{Model ARIMA}

Proses Autoregressive Integrated Moving Average (ARIMA) merupakan penggabungan antara Autoregressive (AR) dan Moving Average (MA) serta proses differencing (orde $d$ untuk data non musiman, orde $D$ untuk data musiman) terhadap data runtun waktu. Secara umum, model ARIMA dituliskan sebagai ARIMA $(p, d, q)(P, D, Q)$ dengan model matematis sebagai berikut.

$$
\phi_{p}(B)(1-B)^{d} y_{t}=\theta_{q}(B) \varepsilon_{t}
$$

dan untuk musiman sebagai berikut.

$$
\phi_{p} \phi_{P}\left(B^{S}\right)(1-B)^{d}\left(1-B^{S}\right)^{D} y_{t}=\theta_{q} \theta_{Q}\left(B^{S}\right) \varepsilon_{t}
$$


Keterangan:

$\phi_{p}=$ parameter regresi diri ordo ke-p

$\theta_{q}=$ parameter rataan bergerak ordo ke-q

$\phi_{p}(B)=\left(1-\phi_{1} B-\phi_{2} B^{2}-\ldots-\phi_{p} B^{p}\right)$

$\theta_{q}(B)=\left(1-\theta_{1} B-\theta_{2} B^{2}-\ldots-\theta_{q} B^{q}\right)$

$\phi_{P}\left(B^{S}\right)=\left(1-\phi_{1} B^{S}-\phi_{2} B^{2 S}-\ldots-\phi_{P} B^{P S}\right)$

$\theta_{Q}\left(B^{S}\right)=\left(1-\theta_{1} B^{S}-\theta_{2} B^{2 S}-\ldots-\theta_{Q} B^{Q S}\right)$

$S=$ musiman

$B$ = pembeda

\section{Model ARIMAX}

Model ARIMAX adalah model ARIMA dengan peubah tambahan (Cryer dan Chan, 2008). Peubah tambahan yang digunakan untuk data deret waktu dengan variasi kalender berupa variabel dummy. Pada pemodelan ini, variabel dummy bernilai 1 untuk waktu-waktu terjadinya hari khusus dan bernilai 0 untuk waktu-waktu selainnya. Model awal dibangun dengan pemodelan regresi linier dengan variabel dummy sebagai peubah prediktor yang akan menghasilkan sisaan. Menurut Box et al. (2015), sisaan yang dihasilkan dari model regresi deret waktu dapat dipastikan saling berkorelasi, sehingga penanganan yang tepat yaitu melalui pemodelan ARIMA pada sisaan model regresi. Model ARIMAX untuk variasi kalender dapat dituliskan sebagai berikut.

$$
\begin{aligned}
& y_{t}=\beta_{0}+\beta_{1} D_{1, t}+\beta_{2} D_{2, t}+\ldots+\beta_{n} D_{n, t}+\frac{\theta_{q}(B) \varepsilon_{t}}{\phi_{p}(B)(1-B)^{d}} \\
& y_{t}=\beta_{0}+\beta_{1} D_{1, t}+\beta_{2} D_{2, t}+\ldots+\beta_{n} D_{n, t}+\frac{\theta_{q} \theta_{Q}\left(B^{S}\right) \varepsilon_{t}}{\phi_{p} \phi_{P}\left(B^{S}\right)(1-B)^{d}\left(1-B^{S}\right)^{D}}
\end{aligned}
$$

Keterangan:

$y_{t}=$ kombinasi linier dari gabungan pengamatan dan sisaan pada waktu-waktu sebelumnya

$D_{1, t}, D_{2, t}, \ldots, D_{n, t}=$ variabel dummy hari-hari khusus

$\beta_{1}, \beta_{2}, \ldots, \beta_{n} \quad=$ parameter variabel dummy hari-hari khusus

$\phi_{p}=$ parameter regresi diri ordo ke-p

$\theta_{q}=$ parameter rataan bergerak ordo ke-q

$\phi_{p}(B)=\left(1-\phi_{1} B-\phi_{2} B^{2}-\ldots-\phi_{p} B^{p}\right)$

$\theta_{q}(B)=\left(1-\theta_{1} B-\theta_{2} B^{2}-\ldots-\theta_{q} B^{q}\right)$

$\phi_{P}\left(B^{S}\right)=\left(1-\phi_{1} B^{S}-\phi_{2} B^{2 S}-\ldots-\phi_{P} B^{P S}\right)$

$\theta_{Q}\left(B^{S}\right)=\left(1-\theta_{1} B^{S}-\theta_{2} B^{2 S}-\ldots-\theta_{Q} B^{Q S}\right)$

$S$ = musiman

$B$ = pembeda

$t \quad=$ bulan dalam 1 tahun

\section{Sumber Data}

Data diperoleh dari Kementrian Perindustrian divisi Pusat Data dan Informasi mengenai data Nilai Ekspor Produk Industri Alas Kaki Indonesia tahun 2010 - 2019. 


\section{Tahapan Penelitian}

Langkah-langkah pembentukan model ARIMAX dengan efek variasi kalender adalah sebagai berikut.

1. Menentukan variabel dummy berdasarkan efek variasi kalender yaitu pada saat libur hari raya Idul Fitri.

2. Pembentukan model regresi dengan variabel dummy.

3. Melakukan uji signifikansi parameter model regresi menggunakan uji t.

4. Melakukan uji kesesuaian model regresi yaitu residual memenuhi asumsi white noise Uji asumsi white noise dilakukan menggunakan uji Ljung-Box.

5. Jika data residual tidak memenuhi asumsi white noise maka dilanjutkan dengan pemodelan ARIMA pada residual.

6. Melakukan uji kestasioneran data residual.

7. Melakukan differencing jika data tidak stasioner.

8. Melakukan estimasi parameter model ARIMA.

9. Melakukan uji signifikansi parameter model ARIMA menggunakan uji t.

10. Melakukan uji kesesuaian model ARIMA yaitu residual memenuhi asumsi white noise dan berdistribusi normal. Uji asumsi white noise dilakukan menggunakan uji Ljung-Box dan uji kenormalan dilakukan menggunakan uji Kolmogorov Smirnov.

11. Melakukan pemilihan model terbaik dengan MSE terkecil.

12. Pembentukan model ARIMAX dengan menggabungkan model regresi dan model ARIMA.

\section{HASIL DAN PEMBAHASAN}

\section{Identifikasi Pola}

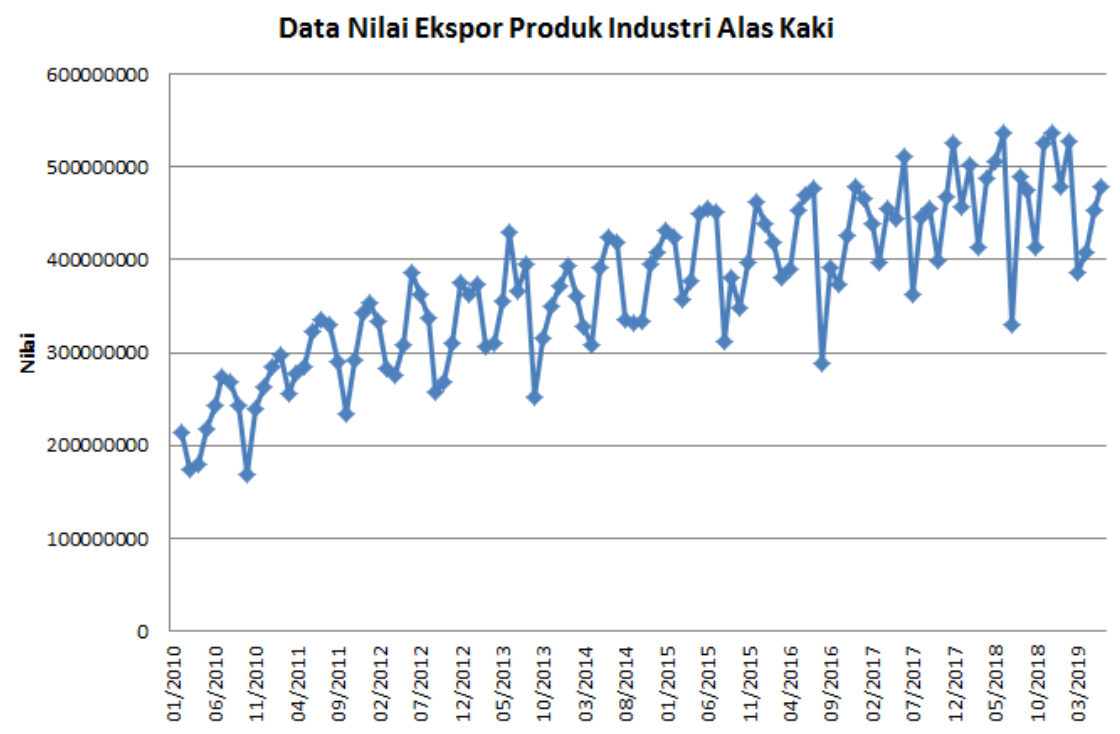

GAMBAR 1. Plot Data Nilai Ekspor Produk Industri Alas Kaki

Gambar 1. menunjukkan bahwa terdapat penurunan pada bulan September 2010 dan 2011, Agustus 2012, 2013, dan 2014, Juli 2015 dan 2016, serta Juni 2017, 2018, dan 2019. Hal ini mengindikasikan 
adanya efek variasi kalender pada data nilai ekspor produk industri alas kaki akibat adanya libur hari raya Idul Fitri yang setiap tahunnya terjadi 11 hari lebih awal dari tahun sebelumnya.

\section{Pemodelan Regresi untuk Efek Variasi Kalender}

Model regresi dummy yang terbentuk dengan efek variasi kalender adalah

$$
y_{t}=380623670-96271067 D_{t}
$$

\section{Uji Signifikansi Model Regresi}

Hasil pengujian secara serentak dapat dilihat pada tabel sbagai berikut.

TABEL 1. Hasil Pengujian Secara Serentak

\begin{tabular}{cc}
\hline Sumber & $\boldsymbol{p}$-value \\
\hline Regresi & 0,001 \\
\hline
\end{tabular}

Berdasarkan Tabel 1. dilihat nilai $p$-value sebesar $0,001<\alpha$ sebesar 0,05 , sehingga $\mathrm{H}_{0}$ ditolak dan disimpulkan variabel bulan yang memuat terjadinya libur hari raya Idul Fitri berpengaruh terhadap variabel nilai ekspor produk industri alas kaki.

Hasil pengujian secara parsial dapat dilihat pada tabel sbagai berikut.

TABEL 2. Hasil Pengujian Secara Parsial

\begin{tabular}{ccc}
\hline Sumber & Koefisien & p-value \\
\hline $\mathrm{B}_{0}$ & 380623670 & 0,000 \\
$\mathrm{~B}_{1}$ & -96271067 & 0,001 \\
\hline
\end{tabular}

Berdasarkan Tabel 2. dilihat kedua nilai $p$-value mempunyai nilai yang $<\alpha$ sebesar 0,05 , sehingga diputuskan $\mathrm{H}_{0}$ ditolak dan disimpulkan konstanta dan variabel bulan yang memuat terjadinya libur hari raya Idul Fitri berpengaruh terhadap variabel nilai ekspor produk industri alas kaki.

\section{Uji Kesesuaian Model Regresi}

\section{Residual}

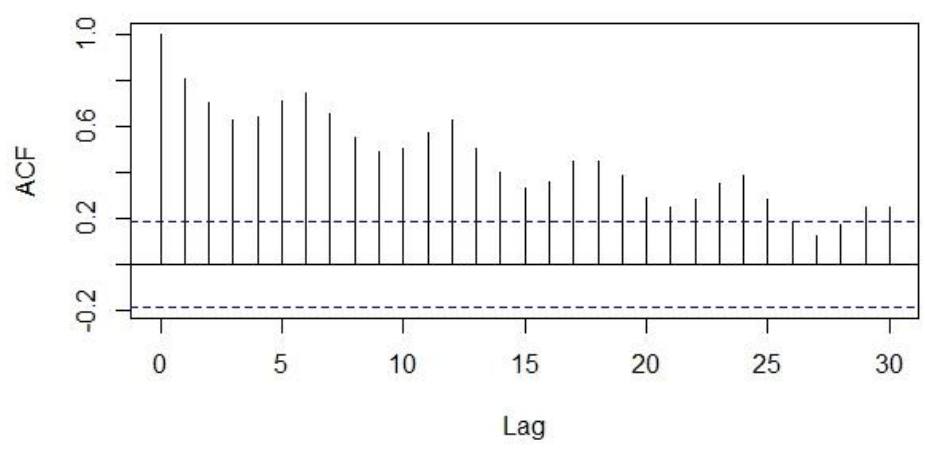

GAMBAR 2. Plot ACF Residual

Berdasarkan plot ACF dan plot PACF pada Gambar 2. residual tidak memenuhi asumsi white noise karena adanya garis yang keluar dari garis signifikansi. Oleh karena itu, akan dilakukan pendugaan model dengan ARIMA. 


\section{Kestasioneran Residual dalam Ragam}

Dilakukan transformasi Box-Cox pada uji kestasioneran dalam ragam. Data dikatakan stasioner dalam ragam jika rounded value pada transformasi Box-Cox bernilai 1. Pada transformasi pertama rounded value bernilai 0,05 sehingga perlu dilakukan transformasi kedua. Setelah melakukan transformasi Box-Cox kedua, rounded value sudah bernilai 1 yang artinya data sudah stasioner dalam ragam.

\section{Kestasioneran Residual dalam Rataan}

Berdasarkan plot ACF Residual pada Gambar 2. diperoleh bahwa data tidak stasioner dalam rataan karena data turun atau naik secara perlahan. Jadi, dibutuhkan pembedaan (differencing) untuk menstasionerkan data tersebut.

\section{Differencing 1}

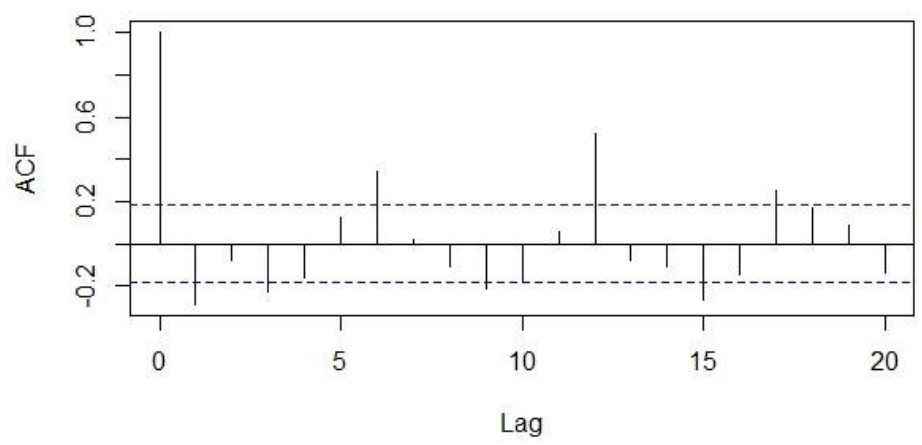

GAMBAR 3. Plot ACF Differencing 1

Berdasarkan hasil pada Gambar 3. terlihat adanya indikasi musiman jika dilihat pada lag 12 dan lag 24 yang melewati garis signifikansi sehingga akan dilakukan differencing musiman dengan lag 12 untuk data residual differencing 1 .

Series d1m1

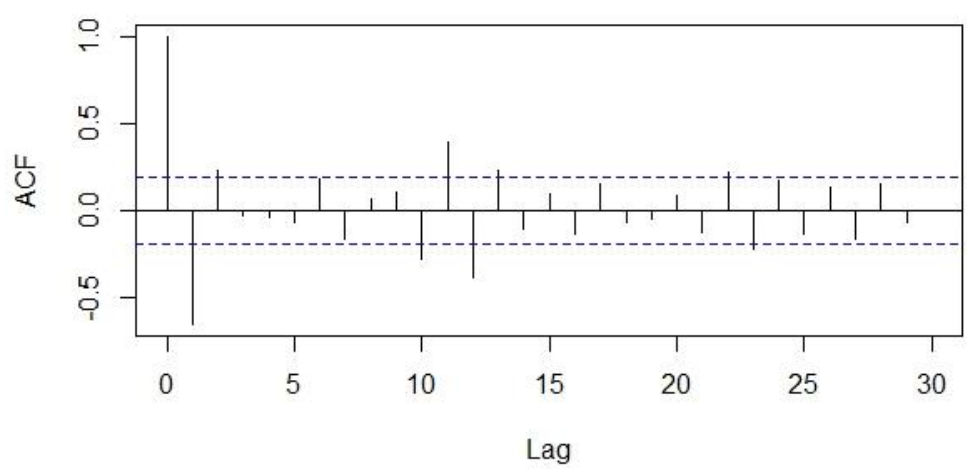

GAMBAR 4. Plot ACF Differencing Musiman

Berdasarkan hasil pada Gambar 4. plot ACF cut-off pada lag ke 1 sehingga data telah dikategorikan stasioner dengan satu kali differencing biasa dan musiman. 


\section{Estimasi Parameter Model ARIMA}

Series d1m1

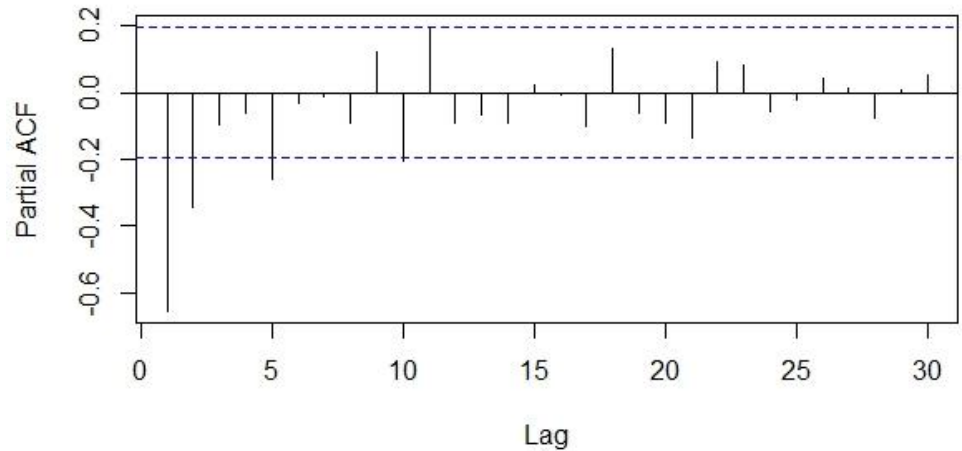

GAMBAR 5. Plot PACF Differencing Musiman

Berdasarkan plot ACF pada Gambar 4. lag terpotong pada lag ke 1, serta plot PACF pada Gambar 5. cenderung naik turun perlahan sehingga model cenderung MA. Sedangkan untuk musiman, plot ACF dan plot PACF memiliki pola naik turun perlahan sehingga model yang didapat adalah $\operatorname{ARIMA}(0,1,1)(0,1,0)^{12}$.

Meskipun model cenderung MA, akan tetapi pada plot PACF dapat dilihat lag 1 dan lag 2 melewati garis signifikansi sehingga dilakukan perluasan pendugaan model dan didapatkan model $\operatorname{ARIMA}(1,1,1)(0,1,0)^{12}$ dan $\operatorname{ARIMA}(2,1,1)(0,1,0)^{12}$.

Uji Signifikansi Parameter Model ARIMA

TABEL 3. Estimasi Parameter Model ARIMA $(0,1,1)(0,1,0)^{12}$

\begin{tabular}{ccc}
\hline & Koefisien & p-value \\
\hline MA 1 & 1,1577 & 0,000 \\
Constant & $-311,39$ & 0,001 \\
\hline
\end{tabular}

TABEL 4. Estimasi Parameter Model ARIMA $(1,1,1)(0,1,0)^{12}$

\begin{tabular}{ccc} 
& Koefisien & p-value \\
\hline AR 1 & 0,2074 & 0,435 \\
MA 1 & 0,9729 & 0,000 \\
Constant & $-222,75$ & 0,000 \\
\hline
\end{tabular}

TABEL 5. Estimasi Parameter Model ARIMA $(2,1,1)(0,1,0)^{12}$

\begin{tabular}{crc}
\hline & Koefisien & p-value \\
\hline AR 1 & $-0,8184$ & 0,040 \\
AR 2 & $-0,5712$ & 0,015 \\
MA 1 & $-0,4078$ & 0,362 \\
Constant & $-468,1$ & 0,479 \\
\hline
\end{tabular}

Tabel 3. menunjukkan bahwa parameter pada model $\operatorname{ARIMA}(0,1,1)(0,1,0)^{12}$ signifikan karena nilai $p$-value $<0,05$ sehingga model ini dapat digunakan. Sedangkan pada Tabel 4. dan Tabel 5. parameter pada model ARIMA $(1,1,1)(0,1,0)^{12}$ dan $\operatorname{ARIMA}(2,1,1)(0,1,0)^{12}$ ada yang tidak signifikan karena ada $p$-value $<0,05$ sehingga kedua model tersebut tidak dapat digunakan.

\section{Uji Kesesuaian Model ARIMA}

Residual telah memenuhi asumsi white noise jika p-value pada Uji Ljung-Box $>0,05$. 
TABEL 6. Hasil Uji Ljung-Box

\begin{tabular}{crrrr}
\hline Lag & $\mathbf{1 2}$ & $\mathbf{2 4}$ & $\mathbf{3 6}$ & $\mathbf{4 8}$ \\
\hline Chi-Square & 10,8 & $*$ & $*$ & $*$ \\
DF & 10 & $*$ & $*$ & $*$ \\
p-value & 0,375 & $*$ & $*$ & $*$ \\
\hline
\end{tabular}

Pada Tabel 6. dapat dilihat nilai p-value > 0,05 yang dapat diartikan bahwa residual model $\operatorname{ARIMA}(0,1,1)(0,1,0)^{12}$ telah memenuhi asumsi white noise.

Residual berdistribusi normal jika p-value pada Uji Kolmogorov-Smirnov > 0,05.

TABEL 7. Hasil Uji Kolmogorov-Smirnov

\begin{tabular}{cc}
\hline Uji & $p$-value \\
\hline Kolmogorov-Smirnov & $>0,150$ \\
\hline
\end{tabular}

Berdasarkan Tabel 7. dapat dilihat nilai $p$-value $>0,05$ yang dapat diartikan bahwa residual model $\operatorname{ARIMA}(0,1,1)(0,1,0)^{12}$ telah berdistribusi normal.

\section{Pemodelan ARIMAX}

Setelah dilakukan uji kesesuaian model dan hanya terdapat satu model yang dapat digunakan, maka model ARIMAX yang terbentuk dari gabungan model regresi dengan model ARIMA adalah sebagai berikut.

$$
y_{t}=380623670-96271067 D_{t}+\frac{(1-1,1577 B)}{(1-B)\left(1-B^{12}\right)} \varepsilon_{t}
$$

\section{Peramalan dengan Model ARIMAX}

Perhitungan peramalan untuk bulan yang tidak terdapat libur hari raya Idul Fitri adalah sebagai berikut.

$$
\begin{aligned}
& y_{7}=380623670-96271067(0)+50666319=431289989 \\
& y_{8}=380623670-96271067(0)+36388776=417012446 \\
& y_{9}=380623670-96271067(0)+3109910=383733580 \\
& y_{10}=380623670-96271067(0)+60013679=440637349 \\
& y_{11}=380623670-96271067(0)+62711590=443335260 \\
& y_{12}=380623670-96271067(0)+24880386=405504056 \\
& y_{1}=380623670-96271067(0)+47811736=428435406 \\
& y_{2}=380623670-96271067(0)+11019510=391643180 \\
& y_{3}=380623670-96271067(0)+340162=380963832 \\
& y_{4}=380623670-96271067(0)+5617050=386240720 \\
& y_{6}=380623670-96271067(0)+3925877=384549547
\end{aligned}
$$

dan perhitungan peramalan untuk bulan yang terdapat libur hari raya Idul Fitri adalah sebagai berikut.

$$
y_{5}=380623670-96271067(1)+12139033=296491636
$$

Pengukuran kesalahan peramalan yang diperoleh adalah MSE $=2952950$. 


\section{KESIMPULAN DAN SARAN}

\section{Kesimpulan}

Berdasarkan hasil analisis dan pembahasan yang telah dilakukan, maka didapatkan model ARIMAX untuk nilai ekspor produk industri alas kaki adalah,

$$
y_{t}=380623670-96271067 D_{t}+\frac{(1-1,1577 B)}{(1-B)\left(1-B^{12}\right)} \varepsilon_{t}
$$

dan hasil peramalan nilai ekspor produk industri alas kaki untuk bulan Juli 2019 sampai dengan bulai Juni 2020 adalah pada tabel berikut.

TABEL 8. Hasil Peramalan Nilai Ekspor Produk Industri Alas Kaki

\begin{tabular}{ccc}
\hline Tahun & Bulan & Nilai \\
\hline & Juli & 431289989 \\
& Agustus & 417012446 \\
& September & 383733580 \\
& Oktober & 440637349 \\
& November & 443335260 \\
& Desember & 405504056 \\
& Januari & 428435406 \\
& Februari & 391643180 \\
& Maret & 380963832 \\
& April & 386240720 \\
& Mei & 296491636 \\
\end{tabular}

Saran

Hal yang disarankan untuk penelitian selanjutnya adalah dapat menggunakan metode metode lain seperti metode Exponential Smoothing Holt-Winters.

\section{UCAPAN TERIMA KASIH}

Terima kasih kepada bidang Analisis Data Pusat Data dan Informasi Kementrian Perindustrian atas ketersediaan data dalam penelitian ini.

\section{REFERENSI}

Astuti, Ayu I. (2013) PEMODELAN RUNTUN WAKTU AUTO REGRESSIVE INTEGRATED MOVING AVERAGEWITH EXOGENOUS VARIABLE (ARIMAX) DENGAN EFEK VARIASI KALENDER, Skripsi, Universitas Pendidikan Indonesia.

Ayu, Karindha F. (2017) Metode Peramalan Menggunakan Model Variasi Kalender, Skripsi, Universitas Lampung.

Ermayanthi, N.M.D., Agus, D. and Suhartono, S. (2012) 'Peramalan Penjualan Buah di Moena Fresh Bali dengan Menggunakan Model Variasi Kalender', Jurnal Sains dan Seni ITS, 1(1), pp.D124D129.

Dila, Mulya. (2017) Penerapan Metode Holt Winter dan Seasonal Arima Pada Peramalan Perkermbangan Wisatawan Mancanegara Yang Datang Ke Indonesia. Thesis (Diploma), Universitas Andalas.

Intan, S.N., Zukhronah, E. and Wibowo, S. (2019) 'Peramalan Banyaknya Pengunjung Pantai Glagah Menggunakan Metode Autoregressive Integrated Moving Average Exogenous (ARIMAX) dengan Efek Variasi Kalender', Indonesian Journal of Applied Statistics, 1(2), pp.70-78. 
Kartiningtyas, A.N., Zukhronah, E. and Sugiyanto, S. (2019) 'Model ARIMAX Untuk Meramalkan Banyak Penumpang dari Pelayaran Dalam Negeri di Pelabuhan Tanjung Priok', Prosiding Sendika, $5(2)$.

Maryati, Wilda. (2019) PENERAPAN MODEL AUTOREGRESSIVE INTEGRATED MOVING AVERAGE WITH EXOGENUS (ARIMAX) DENGAN VARIASI KALENDER, Skripsi, Universitas Lampung.

Noer, Y.S., Darmawan, G. and Pontoh, R.S. (2016) 'Peramalan Jumlah Penumpang Kereta Api Fajar Utama Yogya Jurusan Yogyakarta-Pasar Senen Menggunakan Variasi Kalender ARIMAX (Studi Kasus di Kantor Pusat PT. Kereta Api Indonesia)', Prosiding Seminar Nasional MIPA.

Noor, A., Nohe, D. A. \& Wahyuningsih, S. (2015) 'Peramalan Volume Penjualan Tiket Mobil Dengan Model Variasi Kalender (Studi Kasus: Penjualan Tiket Ferry Khusus Mobil Di Pelabuhan Penyeberangan Kariangau Balikpapan)'. Jurnal EKSPONENSIAL, 6(2), pp.113-120. 